\title{
Identifying Marketable Attributes of Fresh-market Blackberries through Consumer Sensory Evaluations
}

\author{
Renee T. Threlfall \\ Department of Food Science, University of Arkansas System Division of \\ Agriculture, 2650 North Young Avenue, Fayetteville, AR 72704
}

John R. Clark

Department of Horticulture, University of Arkansas System Division of Agriculture, 316 Plant Science, Fayetteville, AR 72701

Aubrey N. Dunteman

Department of Food Science, University of Arkansas System Division of Agriculture, 2650 North Young Avenue, Fayetteville, AR 72704

\author{
Margaret L. Worthington \\ Department of Horticulture, University of Arkansas System Division of \\ Agriculture, 316 Plant Science, Fayetteville, AR 72701
}

Additional index words. appearance, clamshells, composition, fruit, Rubus, taste

\begin{abstract}
Breeding and release of new fresh-market blackberries (Rubus subgenus Rubus Watson) is vital for competitive markets to address evolving changes and production challenges. Physical, composition, and sensory attributes of six University of Arkansas (UA) System Division of Agriculture blackberry cultivars (Caddo, Natchez, Osage, Ouachita, Ponca, and Prime-Ark ${ }^{\circledR}$ Traveler) were evaluated to identify marketable attributes. The consumer sensory study $(n=81)$ had two elements: a visual evaluation of displayed blackberries and an appearance, tasting, and firmness evaluation of the six cultivars using a 9-point verbal hedonic liking scale and a 5-point just about right (JAR) scale. Consumers preferred large blackberries when presented with individual berries of varying sizes and clamshells filled with equal weights of small or large blackberries. The largest of the six cultivars, Natchez and Caddo, were scored favorably for size and shape. Consumers also preferred clamshells with little to no red drupelet reversion, a postharvest disorder where black drupelets on the blackberry turn red during or after cold storage. Consumers did not detect differences in the appearance or firmness of the cultivars and rated the firmness of all cultivars favorably on the JAR scale. The physical and composition attributes of the six cultivars were within commercially acceptable ranges (soluble solids $=9 \%$ to $10 \%, \mathrm{pH}=3.1-3.8$, titratable acidity $=0.6 \%$ to $1.4 \%$, and berry weight $=$ 6-10 g). 'Ponca', 'Osage', 'Caddo', and 'Natchez' were all rated highly for sweetness, sourness, overall flavor, and overall impression. 'Ponca' was rated high for sweetness, overall flavor, and overall impression and had $10.4 \%$ soluble solids, $0.82 \%$ titratable acidity, and a 12.8 soluble solids/titratable acidity ratio. The identification of these marketability attributes of fresh-market blackberries will provide information to advance breeding efforts for fruit with commercial potential.
\end{abstract}

Blackberry (Rubus subgenus Rubus Watson) is one of the best examples of a wild-harvested specialty crop that moved to commercial use through increased consumer demand, targeted breeding efforts, advanced production methods, and year-round availability. The

Received for publication 29 Sept. 2020. Accepted for publication 23 Oct. 2020.

Published online 24 November 2020.

This research was funded by a grant from the Southern Region Small Fruit Consortium.

R.T.T. is the corresponding author. E-mail: rthrelf@ uark.edu.

This is an open access article distributed under the CC BY-NC-ND license (https://creativecommons. org/licenses/by-nc-nd/4.0/). tion of fruit quality. The incidence and severity of red drupelet reversion is affected by environmental conditions, postharvest handling practices, and cultivar choice (Edgley et al., 2019a, 2019b, 2019c; McCoy et al., 2016; Perkins-Veazie et al., 1996; Salgado and Clark, 2016; Segantini et al., 2017, 2018). White drupelet disorder (tan-to-white discoloration of drupelets) is another physiological disorder in blackberries that reduces marketability. Researchers have hypothesized that white drupelet disorder is caused by excessive ultraviolet-B radiation or visible light. However, unlike red drupelet reversion, white drupelet disorder seems to be cultivar-specific, and breeders have been able to effectively select against susceptibility to this disorder (Stafne et al., 2017).

The improvement of blackberry flavor and firmness are important objectives in the University of Arkansas (UA) System Division of Agriculture breeding program. Firm blackberries generally perform better for many postharvest quality parameters (Finn and Clark, 2012, 2017), and better and unique flavors appeal to consumers. Fruit firmness was long considered a difficult or intractable trait to improve, but sustained breeding efforts over decades have resulted in major advances in shipping quality and firmness in the UA System blackberry breeding program (Clark, 2005). Firm blackberries were reported to have significantly less red drupelet reversion than soft genotypes (cultivars and selection) during storage (Edgley et al., 2019a, 2019b, 2019c; McCoy et al., 2016; Salgado and Clark, 2016; Segantini et al., 2017, 2018). However, it is unknown whether consumers will embrace blackberries with extremely firm flesh. It is also unclear how firmness and appearance (including red drupelet reversion) compare with other taste attributes such as astringency, acidity, sweetness, and aromatics that might drive consumer purchasing.

Consumers want a berry that is uniform in color, fresh, fair-priced, rich in nutraceuticals, has a good shelf life, and has unique flavors and aromas (Threlfall et al., 2020). Some sensory research, mostly on appearance, basic tastes, and flavor, has been done to profile processing blackberries grown in the northwestern United States (Cavender et al., 2014; de Souza et al., 2014; Du et al., 2010a, 2010b; Kurnianta et al., 2005) and fresh-market blackberries grown in the Southeast (Segantini et al., 2017, 2018; Threlfall et al., 2016a, 2016b, 2020). Kurnianta (2005) evaluated 10 thornless blackberry selections in comparison with the standard 'Marion' and developed a lexicon of 21 aroma descriptors. Du et al. (2010a, 2010 b) profiled the flavor of 'Marion' blackberries and found blackberry genotypes from the Pacific Northwest had diverse descriptive sensory aroma profiles. de Souza et al. (2014) profiled sensory attributes of blackberries that had been frozen and thawed using different methods compared with a fresh control. Cavender et al. (2014) investigated the 
sensory profiles and antioxidant properties of blackberries grown using different weed management strategies.

Threlfall et al. (2016b) developed a freshmarket blackberry lexicon in an evaluation of UA System blackberries for descriptive sensory analysis and showed that panelists were not able to differentiate sweetness among blackberry genotypes but could easily differentiate sourness and overall aromatic impact. Using this previously developed lexicon, Segantini et al. (2017) found that descriptive sensory panelists could not differentiate color, glossiness, firmness, or sweetness after storage but could identify the blackberries as being more astringent and less sour and bitter after storage.

Appearance of blackberries, both as an individual berry or a group of berries in a clamshell, is important because consumers at commercial retail locations make purchase decisions based on appearance. Because blackberries are typically sold in transparent, plastic clamshells, the consumer can see the berries before purchasing. Studies have shown that consumers want glossy, black berries with a uniform size and few to no blemishes (Mikulic-Petkovsek et al., 2012; Segantini et al., 2017; Threlfall et al., 2016b). Using an online survey, Threlfall et al. (2020) collected data on blackberry consumer demographics, purchase and consumption habits, and preferences for appearance of individual blackberries and groups of blackberries in clamshell containers. The survey was completed by 879 blackberry consumers who were $76.7 \%$ female from ages 21 to 40 $(47.2 \%), 41$ to $60(36.0 \%)$, and 61 and over $(16.8 \%)$ with varying levels of education and incomes. The survey showed that consumers preferred large, oblong blackberries and blackberries with fewer red drupelets.

There is a critical need to determine the key sensory attributes that drive consumer preference to steer breeding decisions and help U.S. growers better market their blackberries. Although the online survey (Threlfall et al., 2020) provided unique data to characterize consumer perception and purchasing habits of fresh-market blackberries, the presentation order of the images of blackberries was unrandomized, and the consumers did not get to taste the blackberries. The objective of this research was to identify marketable attributes of fresh-market blackberries through evaluations of physical, composition, and sensory attributes that allow consumers to assess appearance, flavor, and firmness.

\section{Materials and Methods}

\section{Blackberry plants and culture}

Six blackberry cultivars (Caddo, Natchez, Osage, Ouachita, Ponca, and Prime-Ark ${ }^{\circledR}$ Traveler) were evaluated in this study. The plants were grown at the UA System Fruit Research Station in Clarksville, AR (West Central Arkansas, lat. $35^{\circ} 31^{\prime} 58^{\prime \prime} \mathrm{N}$, long. $93^{\circ} 24^{\prime} 12^{\prime \prime} \mathrm{W}$ ). Plants were trained to a Ttrellis with two parallel lower wires $\approx 0.5 \mathrm{~m}$ from the soil surface spaced $0.5 \mathrm{~m}$ apart and two parallel upper wires $\approx 1.0 \mathrm{~m}$ high spaced $0.8 \mathrm{~m}$ apart. Dormant pruning consisted of removing dead floricanes and removing primocane tissue to a point below the flowering area on the primocanes. The plants were irrigated as needed using trickle irrigation. Standard cultural and pesticide practices for erect blackberry production for this region were used (Southern Region Small Fruits Consortium, 2020).

\section{Blackberry harvest}

Blackberries were harvested on 25 June 2019 at the shiny-black stage of ripeness and were free of major blemishes, flaws, or damage. Approximately $4 \mathrm{~kg}$ of fruit was harvested from each of the six cultivars. Fruit was harvested directly into $240 \mathrm{~g}$ (pint), lowprofile vented clamshells, placed in chilled coolers and transported to the UA System Department of Food Science, Fayetteville. A random sample of fruit was collected from the harvest clamshells and used for physical, composition, and sensory analyses. A 200 -g sample of each cultivar was frozen $\left(-10{ }^{\circ} \mathrm{C}\right)$ in triplicate for physical and composition analysis, and the remainder of the fruit was stored overnight in clamshells at $2{ }^{\circ} \mathrm{C}$ for consumer sensory analysis.

\section{Physical and composition analysis}

Physical and composition attributes of each of the fresh-market blackberry cultivars were evaluated. Three replicate samples of $\approx 200 \mathrm{~g}$ of berries for each cultivar were stored at $-10{ }^{\circ} \mathrm{C}$ until analysis.

Physical attributes. Five berries per cultivar and replication were used to determine physical attributes (individual berry weight, length, and width). The five-berry samples were weighed on a digital scale, and the width and length of each blackberry were measured with digital calipers.

Composition attributes. Three replicate five-berry samples of each cultivar were used to determine composition attributes (soluble solids, $\mathrm{pH}$, and titratable acidity). Samples were placed in cheesecloth to extract the juice from the berries. Total soluble solids (expressed as \%) of the juice was measured with a Bausch \& Lomb Abbe Mark II refractometer (Scientific Instruments, Keene, NH). Titratable acidity and $\mathrm{pH}$ of the juice were measured with a Metrohm 862 Compact Titrosampler (Metrohm AG, Herisau, Switzerland) fitted with a $\mathrm{pH}$ meter. Titratable acidity was determined using $3 \mathrm{~g}$ of juice diluted with $50 \mathrm{~mL}$ of deionized, degassed water by titration with $0.1 \mathrm{~N}$ sodium hydroxide $(\mathrm{NaOH})$ to an endpoint of $\mathrm{pH} 8.2$; results were expressed as $\mathrm{g} / \mathrm{L}$ citric acid. Soluble solids/titratable acidity ratio was calculated.

\section{Consumer sensory analysis}

The consumer sensory evaluation was done at the UA System Sensory Science Center, Fayetteville. The consumers $(\mathrm{n}=$ 81) were recruited from a database $(\mathrm{n} \approx 5500)$ and selected based on consumption, purchasing habits, and liking of fresh blackberries. The consumers evaluated the fresh-market blackberries and were paid with gift card incentives. Consumers were also asked demographic questions (gender, age group, education, and income) and questions regarding purchase and consumption habits for fresh blackberries. The consumer sensory study had two elements: a visual evaluation of displayed fresh blackberries and an appearance, tasting, and firmness evaluation of the fresh blackberries.

Visual evaluation. The consumers evaluated five visual displays before evaluating the appearance, taste, and firmness of the six UA System blackberry cultivars. Fruit for the visual displays were also harvested from the Fruit Research Station. The consumers were shown displays of individual blackberries and groups of blackberries in clamshell containers and asked to provide ranking or preference for various attributes. Consumers were shown three displays of individual blackberries (three berries of different shapes, three berries of different sizes, and six berries of different shapes and sizes). Two displays of blackberries in clamshells were shown to consumers. The first clamshell display consisted of one clamshell filled with large berries (10- to 12-g berries) and one with small berries (4- to 5-g berries). The second display had three clamshells filled with blackberries with increasing levels of red drupelets. The sample presentation order within each display was randomized and balanced so that the different samples appeared the same number of times at each presentation position. Consumers responded to questions on a paper ballot.

Appearance, tasting, and firmness evaluation. Consumers evaluated the appearance, taste, and firmness of the same cultivars (Caddo, Natchez, Osage, Ouachita, Ponca, and PrimeArk $^{\circledR}$ Traveler) evaluated for physical and composition attributes. The sample presentation order was randomized and balanced so that the different cultivars appeared the same number of times at each presentation position. Samples were served one cultivar at a time to each consumer. Sample plates were labeled with three-digit codes, and each panelist was served four berries. Unsalted crackers and water were provided for palate cleansing between samples. Each consumer was asked to evaluate eight attributes (appearance, size, shape, overall flavor, overall impression, sweetness, sourness, and firmness) on the 9-point verbal hedonic scale $(1=$ dislike extremely; $9=$ like extremely), and five attributes (size, blackberry flavor, sweetness, sourness, and firmness) on a 5-point JAR scale ( $1=$ not nearly enough; $3=$ just about right; $5=$ much too much). Data were acquired using a computerized sensory data acquisition system (Compusense 5 version 5.0, Compusense, Guelph, Canada).

\section{Statistical design and analyses}

Analysis was conducted using JMP (version 14.0; SAS Institute Inc., Cary, NC) using a univariate analysis of variance (ANOVA). 
Table 1. Physical and composition attributes of fresh-market blackberry cultivars, Clarksville, AR (2019).

\begin{tabular}{lccccccc}
\hline Cultivar & $\begin{array}{c}\text { Berry } \\
\mathrm{wt}(\mathrm{g})\end{array}$ & $\begin{array}{c}\text { Berry } \\
\text { length }(\mathrm{mm})\end{array}$ & $\begin{array}{c}\text { Berry } \\
\text { width }(\mathrm{mm})\end{array}$ & $\begin{array}{c}\text { Soluble } \\
\text { solids }(\%)\end{array}$ & $\mathrm{pH}$ & $\begin{array}{c}\text { Titratable acidity } \\
(\% \text { citric })\end{array}$ & $\begin{array}{c}\text { Soluble solids/titratable } \\
\text { acidity ratio }\end{array}$ \\
\hline Caddo & $9.15 \mathrm{ab}^{2}$ & $33.28 \mathrm{a}$ & $23.87 \mathrm{ab}$ & $8.50 \mathrm{a}$ & $3.10 \mathrm{c}$ & $1.33 \mathrm{a}$ & $6.44 \mathrm{bc}$ \\
Natchez & $9.98 \mathrm{a}$ & $34.67 \mathrm{a}$ & $25.55 \mathrm{a}$ & $9.33 \mathrm{a}$ & $3.13 \mathrm{c}$ & $1.37 \mathrm{a}$ & $0.80 \mathrm{abc}$ \\
Osage & $4.83 \mathrm{~d}$ & $22.93 \mathrm{c}$ & $21.84 \mathrm{~b}$ & $9.80 \mathrm{a}$ & $3.83 \mathrm{a}$ & $0.64 \mathrm{~b}$ & $15.39 \mathrm{ab}$ \\
Ouachita & $7.74 \mathrm{abc}$ & $27.81 \mathrm{~b}$ & $23.85 \mathrm{ab}$ & $9.30 \mathrm{a}$ & $3.21 \mathrm{bc}$ & $1.61 \mathrm{a}$ & $5.87 \mathrm{c}$ \\
Ponca & $6.70 \mathrm{~cd}$ & $26.36 \mathrm{bc}$ & $22.21 \mathrm{~b}$ & $10.40 \mathrm{a}$ & $3.54 \mathrm{ab}$ & $0.82 \mathrm{~b}$ & $12.83 \mathrm{abc}$ \\
Prime-Ark & $6.97 \mathrm{bcd}$ & $28.91 \mathrm{~b}$ & $22.66 \mathrm{~b}$ & $9.50 \mathrm{a}$ & $3.63 \mathrm{a}$ & $0.67 \mathrm{~b}$ & $15.85 \mathrm{a}$ \\
$P$ value & $<0.0001$ & $<0.0001$ & 0.0002 & 0.0668 & $<0.0001$ & $<0.0001$ & 0.0053 \\
\hline
\end{tabular}

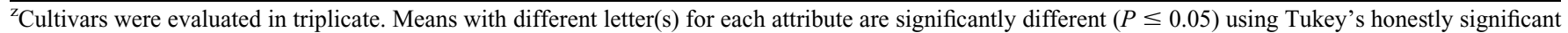
difference test.

Tukey's honestly significant difference was used for mean separation. The physical and composition data were analyzed as a completely randomized design with three replicates per cultivar. For the consumer sensory, a univariate ANOVA was used to detect the significance of the cultivar main effect for each hedonic-scaled attribute, and the panelist main effect was included to account for between-panelist variation. Nine-point hedonic scales were converted to numerical values (dislike extremely $=1$, dislike very much $=2$, dislike moderately $=3$, dislike slightly $=4$, neither like nor dislike $=5$, like slightly $=6$, like moderately $=7$, like very much $=8$, and like extremely $=9$ ) for statistical analysis. For JAR-scale attributes, a collapsed scale was used (too low, JAR, and too much), and the percent of responses for each attribute were tabulated.

\section{Results and Discussion}

\section{Physical and composition attributes of fresh-market blackberries}

Physical and composition attributes of the fresh-market blackberry cultivars were evaluated (Table 1). For these cultivars, all the physical and composition attributes were significant except soluble solids.

Physical attributes. 'Natchez' had the highest berry weight ( $9.98 \mathrm{~g})$, longest berry $(34.67 \mathrm{~mm})$, and widest berry $(25.55 \mathrm{~mm})$, whereas 'Osage' had the lowest berry weight $(4.83 \mathrm{~g})$, shortest berry $(22.93 \mathrm{~mm})$, and narrowest berry $(21.84 \mathrm{~mm})$. Threlfall et al. (2016b) found UA System blackberries grown at the Fruit Research Station in Clarksville, AR, had berry weights from 6 to $14 \mathrm{~g}$ and suggested that a commercially marketed fresh-market blackberry should have a berry weight of 8 to $10 \mathrm{~g}$. The average berry weights of 'Natchez' and 'Osage' reported by Threlfall et al. (2016b), $14.26 \mathrm{~g}$ and $7.29 \mathrm{~g}$, respectively, were larger than in the current study. This suggests that berry size varies from year to year, even in the same location and with the same cultural practices.

Composition attributes. The cultivars evaluated in this study had composition values that mostly fell within the ranges found in previous studies with a $\mathrm{pH}$ from 3.0 to 3.6 , titratable acidity from $0.7 \%$ to $1.4 \%$, and soluble solids from $8 \%$ to $11 \%$. In a consumer study, Threlfall et al. (2016b) found that fresh-market blackberries should have soluble solids of $9 \%$ to $11 \%$, titratable

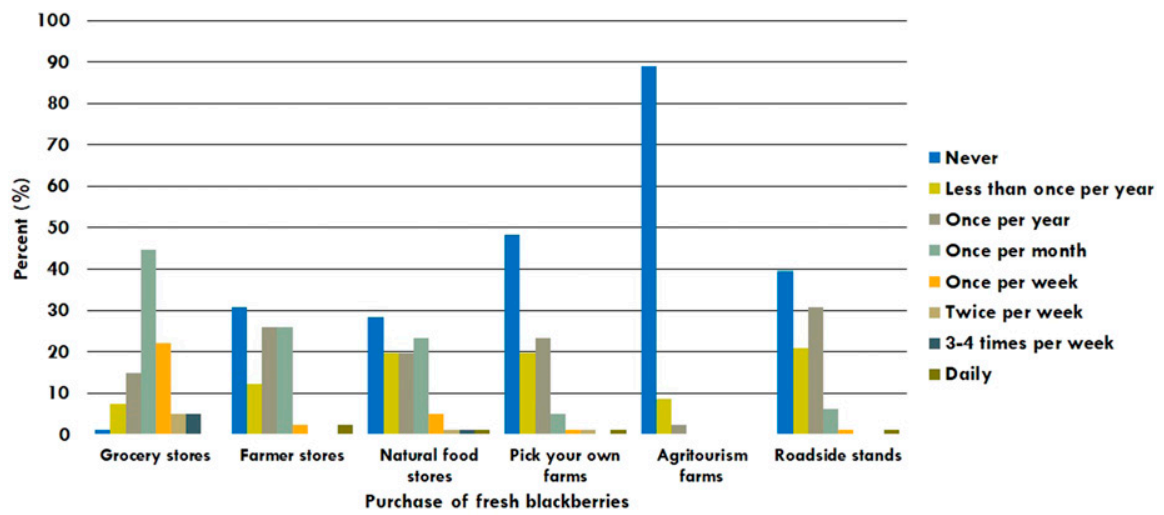

Fig. 1. Percent of consumer $(n=81)$ responses when asked, "How often do you purchase fresh-market blackberries from these locations?"

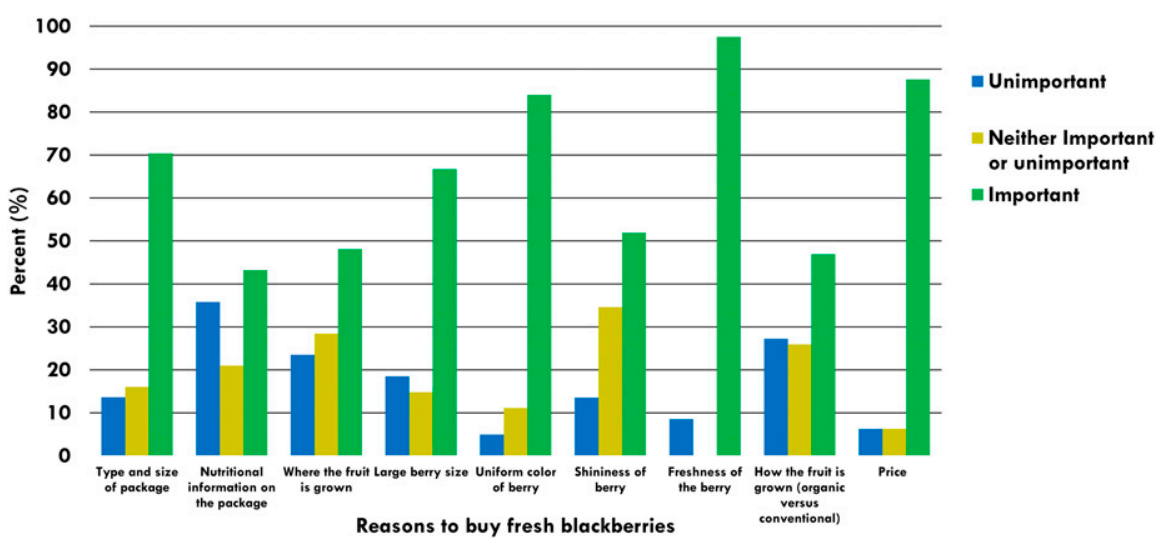

Fig. 2. Percent of consumer $(n=81)$ responses when asked, "If you were going to buy fresh blackberries, please rate the importance of the reason(s) for your decision to buy them."

acidity of $0.9 \%$ to $1.0 \%$, and a soluble solids/ titratable acidity ratio of 10 to 13 . The soluble solids of the blackberries in the current study ranged from $8.50 \%$ to $10.40 \%$, but there was not a significant difference among cultivars. The $\mathrm{pH}$ of 'Osage' (3.83) was the highest and 'Caddo' (3.10) the lowest. 'Ouachita' $(1.61 \%)$ had the highest titratable acidity. None of the cultivars in this study fell in the titratable acidity range of $0.9 \%$ to $1.0 \%$, which was determined to be optimal by Threlfall et al. (2016b). 'Osage', 'Ponca', and 'Prime-Ark ${ }^{\circledR}$ Traveler' had soluble solids/titratable acidity ratios of 12.83 to 15.85 and 'Caddo', 'Natchez', and 'Ouachita' had ratios of 5.87 to 6.80 . On the basis of Threlfall et al.'s (2016b) findings on ideal composition parameters for fresh-market blackberries, 'Ponca' had the most ideal composition of the cultivars evaluated, with a 12.83 soluble solids/titratable acidity ratio, $10.40 \%$ soluble solids, and $0.82 \%$ titratable acidity.

\section{Consumer sensory attributes of fresh- market blackberries}

Consumer demographics. Consumers participating in this study were $46.9 \%$ female, and $60.5 \%$ were married. Ages of consumers ranged from less than 21 to more than 70 years, with the largest percentage between the ages of 31 and 40 years $(34.6 \%)$. The level of education of the consumers ranged from high school to graduate school. A 4-year degree was the highest level of education for $30.7 \%$ of consumers and 
some college for $43.2 \%$ of the consumers. Although annual gross incomes ranged from under $\$ 20,000$ to more than $\$ 200,000$ USD, nearly half of consumers earned $\$ 20,000$ to 60,000 USD (46.9\%) (data not shown). In comparison, the respondents of the previously published online survey were mostly female (76.7\%) and aged 21 to $40(47.2 \%)$ and 41 to $60(36.0 \%)$ with varying levels of education and incomes (Threlfall et al., 2020). The online study had $\approx 30 \%$ more females than this in-person consumer study.

Consumer purchasing and consumption habits. The consumers were asked about purchasing and consumption habits of freshmarket blackberries. Reasons for purchasing blackberries included for personal consumption $(91.4 \%)$, for consumption with family or friends $(90.1 \%)$, as a dessert $(87.7 \%)$, for a special occasion $(80.2 \%)$, or with a meal (66.7\%) (data not shown). Places that consumers purchased blackberries included grocery stores, farmer stores, natural food stores, pick your own farms, agritourism farms, and roadside stands (Fig. 1). Consumers purchased blackberries at grocery stores $(44.5 \%)$ and farmer stores $(30.9 \%)$ at least once a month. Whereas in the online survey, the consumers purchased blackberries once per month at grocery stores (33.6\%) and once per year, $30 \%$ of the consumers purchased at either grocery stores, farmer stores, or roadside stands (Threlfall et al., 2020). Interestingly, $88.9 \%$ of the consumers in this study responded that they never purchased blackberries at agritourism farms, $48.1 \%$ at pick your own farms, and $39.5 \%$ at roadside stands. A total of $28.4 \%$ consumers responded that they ate blackberries once per month, $24.5 \%$ two to three times per month, $17.3 \%$ less than once per month, and $16.0 \%$ once per week (data not shown). Whereas in the online survey, more consumers ate fresh blackberries once per month (41.6\%), followed by $29.1 \%$ once per year, and $12.2 \%$ once per week.

The consumers were asked about important factors they consider when purchasing fresh-market blackberries. More than $65 \%$ of the consumers indicated the type and size of package, large berry size, uniform color of berry, freshness of berry, and price were important factors when purchasing blackberries (Fig. 2). The freshness of berries $(97.5 \%)$, price $(87.6 \%)$, and uniform berry color $(80.0 \%)$ were the three most important factors considered when consumers purchase fresh-market blackberries. These results were similar to the online survey by Threlfall et al. (2020), where the freshness of the berries $(98.1 \%)$ and the price $(87.8 \%)$ were rated highest as reasons to buy fresh blackberries.

Consumer visual evaluation of individual blackberries. The participants were asked to evaluate the shape, size, and overall appearance of individual blackberries with a U.S. quarter and ruler shown as a reference (Fig. 3). The blackberries were labeled with random, threedigit numbers which the participants were asked to rank from most to least preferred.

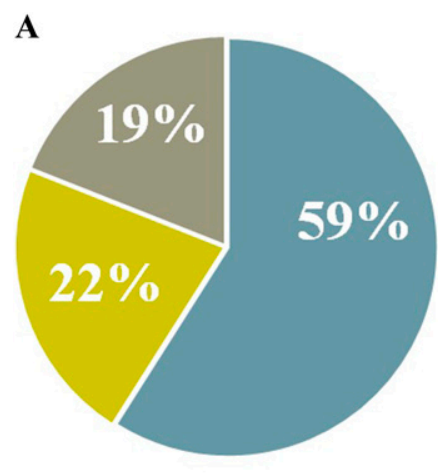

$\because 825=718=316$
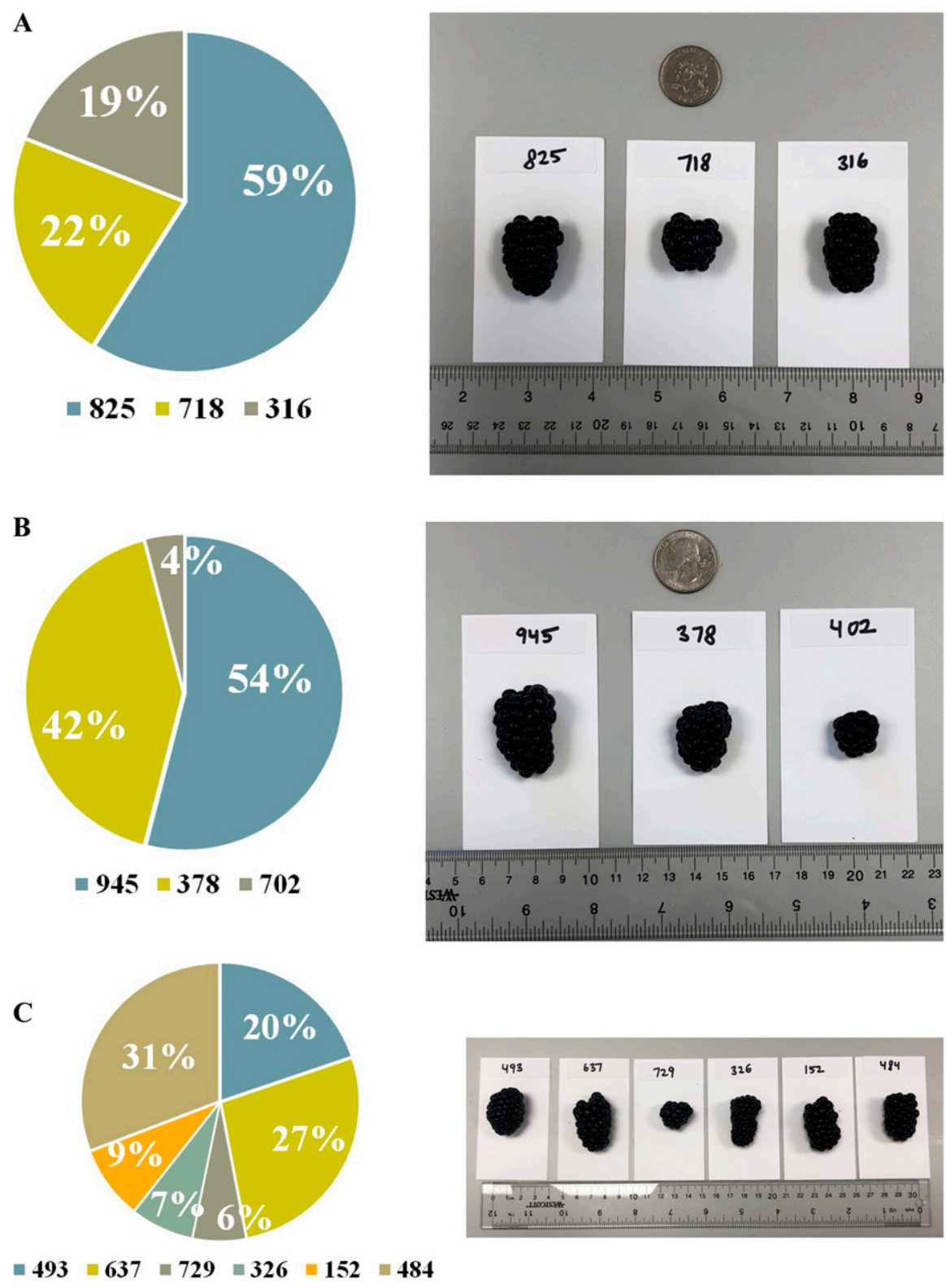

Fig. 3. Percent of consumers $(n=81)$ who ranked blackberries as most preferred for shape $(\mathbf{A})$, size $(\mathbf{B})$, and overall appearance $(\mathbf{C})$.

Blackberry shape. The consumers were asked to evaluate the shape of three blackberries: one that was cone-shaped oblong (' 825 '), one that was round (' 718 '), and one that was cylinder-shaped and oblong ('316') (Fig. 3A). Approximately $59.3 \%$ of the consumers preferred the blackberry ' 825 ', followed by $22.2 \%$ preferring ' 718 ', and $18.5 \%$ preferring ' 316 '. The consumers preferred the shape of the cone-shaped oblong blackberry, as did the participants $(68.5 \%)$ in the online survey (Threlfall et al., 2020).

Blackberry size. The consumers were asked to evaluate the size of three blackberries: one that was twice as large as the U.S. quarter ('945'), one slightly larger than the quarter ('378'), and one that was slightly smaller than the quarter ('402') (Fig. 3B). Approximately $54.3 \%$ of consumers preferred the size of blackberry ' 945 ', followed by $42.0 \%$ preferring ' 378 ', and $3.7 \%$ preferring ' 402 '. The consumers preferred the largest blackberry, as did the majority of participants $(53.6 \%)$ in the online survey (Threlfall et al., 2020).

Blackberry overall appearance. The consumers were asked to evaluate the overall appearance of six blackberries with different sizes and shapes (Fig. 3C). The consumers preferred blackberry '484' (a large, coneshaped, oblong berry) most (31\%), whereas ' 729 ' (a small, round berry) was least preferred $(6 \%)$. In general, consumers preferred blackberries that were oblong as opposed to round and large rather than small. These results were also consistent with the participants in the online survey (Threlfall et al., 2020).

Consumer visual evaluation of blackberries in clamshells. The consumers were asked to evaluate clamshells filled with blackberries 
(Fig. 4). The clamshells were labeled with random, three-digit numbers, which the consumers were asked to rank from most to least preferred.

Size of blackberries in clamshells. The consumers were asked to evaluate two clamshells: one filled with large berries and the other filled with small berries (Fig. 4A). The clamshells had the same weight of berries in each but a different number of berries. There were about twenty-two 10 - to 12 -g berries in clamshell ' 735 ' and about fifty 4- to 5-g berries in clamshell ' 916 '. When asked which container of blackberries they would prefer to purchase, $56.8 \%$ of the consumers preferred clamshell ' 735 ' (clamshell of large berries) followed by $43.2 \%$ preferring ' 916 ' (clamshell of small berries). Consumers preferred clamshells containing larger blackberries as opposed to clamshells containing smaller blackberries, which was consistent with the participants in the online survey, where $68.8 \%$ preferred the clam-

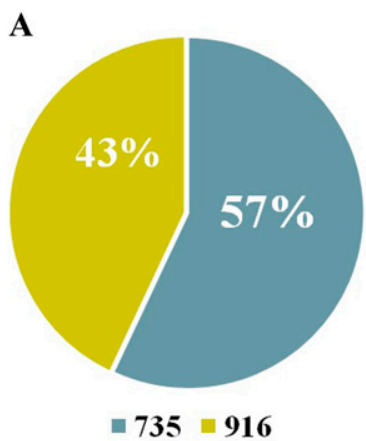

B

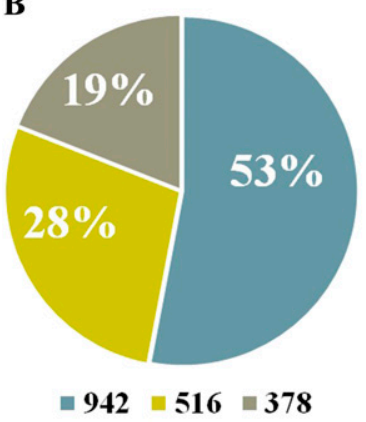

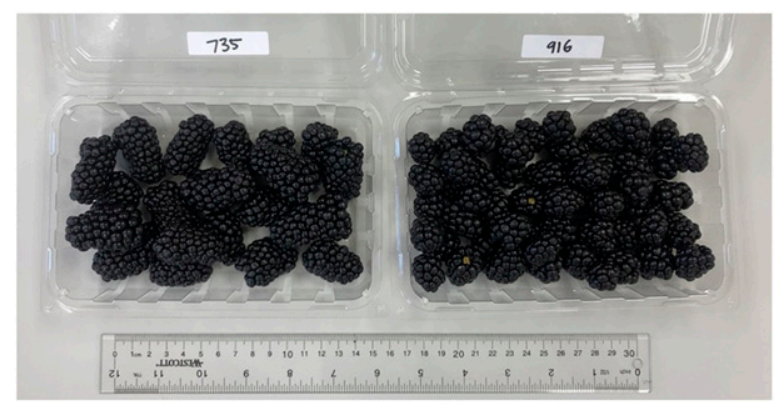

Larger berries

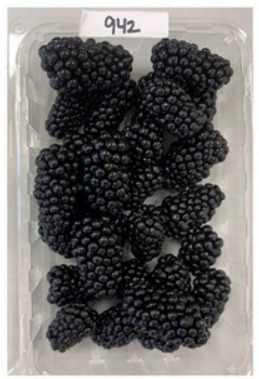

No red drupelets

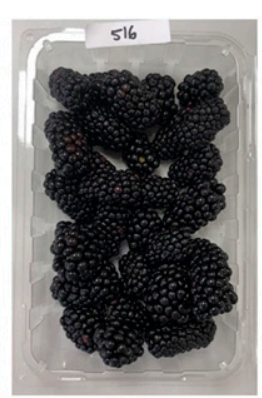

Some red drupelets More red drupelets

Fig. 4. Percent of consumers $(n=81)$ who ranked clamshells of blackberries as most for different size berries (A) and different amounts of red drupelet reversion (B). Clamshell ' 735 ' had about twenty-two 10- to 12-g berries, and ' 916 ' had about fifty 4- to 5-g berries. Clamshell ' 942 ' had $0 \%$ of the blackberries with red drupelet reversion, ' 516 ' had about $25 \%$, and ' 378 ' had $65 \%$.

shell containing larger blackberries (Threlfall et al., 2020).

Red drupelet reversion of blackberries in clamshells. The consumers were asked to evaluate three clamshells filled with blackberries with varying levels (none, some, and more) of red drupelet reversion (Fig. 4B). Each clamshell had $\approx 25$ berries. Clamshell ' 942 ', ' 516 ', and ' 378 ' had $0 \%, 25 \%$, and $\approx 65 \%$ of the blackberries with red drupelet reversion, respectively. When asked which container of blackberries they would prefer to purchase, $53.1 \%$ of the consumers preferred clamshell '942' (no red drupelet reversion), followed by $28.4 \%$ preferring ' 516 ' (some red drupelet reversion), and $18.5 \%$ preferring clamshell ' 378 ' (most red drupelet reversion). When shown three clamshell containers of blackberries with increasing levels of red drupelets, $72.9 \%$ of the participants in the online survey preferred blackberries with the fewest red drupelets, $20.1 \%$ preferred the midlevel, and $7.0 \%$ preferred the clamshell with the most red drupelets (Threlfall et al., 2020). Consumers were aware of the presence of red drupelet reversion on the blackberries, and they preferred blackberries with the fewest red drupelets.

Consumer appearance, tasting, and firmness evaluation. The liking scores presented in Table 2 for all the fresh-market blackberry attributes evaluated ranged from 5 (neither like nor dislike) to 7 (like moderately). Consumer panelists liked the appearance (6.6-7.1) and firmness (6.4-6.9) of the blackberries, but did not indicate differences in liking among cultivars. 'Caddo', a 9-g berry that was $33 \times 24 \mathrm{~mm}$, had the highest score for the liking of size and shape. 'Ponca' had the highest liking for overall impression, flavor, sweetness, and sourness. 'Ponca' had $10.40 \%$ soluble solids, $0.82 \%$ titratable

Table 2. Consumer sensory $(n=81)$ attributes of fresh-market blackberry cultivars evaluated on a 9-point hedonic scale $(1=$ dislike extremely; $5=$ neither like nor dislike; 9 = like extremely), Clarksville, AR (2019).

\begin{tabular}{|c|c|c|c|c|c|c|c|c|}
\hline Genotype & Appearance & Size & Shape & Overall impression & Overall flavor & Sweetness & Sourness & Firmness \\
\hline Osage & $6.6 \mathrm{a}$ & $6.0 \mathrm{c}$ & $6.4 \mathrm{c}$ & $6.6 \mathrm{ab}$ & $6.7 \mathrm{a}$ & $6.2 \mathrm{~b}$ & $5.9 \mathrm{ab}$ & $6.6 \mathrm{a}$ \\
\hline Ouachita & $6.7 \mathrm{a}$ & $6.4 \mathrm{bc}$ & $6.7 \mathrm{abc}$ & $5.7 \mathrm{c}$ & $5.5 \mathrm{c}$ & $4.9 \mathrm{~d}$ & $4.9 \mathrm{c}$ & $6.7 \mathrm{a}$ \\
\hline Prime-Ark ${ }^{\circledR}$ Traveler & $6.6 \mathrm{a}$ & $6.4 \mathrm{bc}$ & $6.5 \mathrm{c}$ & $6.3 \mathrm{~b}$ & $6.0 \mathrm{~b}$ & $5.6 \mathrm{c}$ & $5.3 \mathrm{bc}$ & $6.4 \mathrm{a}$ \\
\hline$P$ value & 0.2132 & 0.0003 & 0.0117 & $<0.0001$ & $<0.0001$ & $<0.0001$ & 0.0004 & 0.3214 \\
\hline
\end{tabular}

${ }^{\mathrm{z}}$ Means with the different letters for each attribute are significantly different $(P \leq 0.05)$ using Tukey's honestly significant difference test.

Table 3. Percent $(\%)$ of consumer sensory $(n=81)$ attributes for fresh-market blackberry cultivars on a collapsed 5-point just about right $(\mathrm{JAR})^{\mathrm{z}}$ scale, Clarksville, AR (2019).

\begin{tabular}{|c|c|c|c|c|c|c|c|c|c|c|c|c|c|c|c|}
\hline \multirow[b]{2}{*}{ Cultivar } & \multicolumn{3}{|c|}{ Size } & \multicolumn{3}{|c|}{ Blackberry flavor } & \multicolumn{3}{|c|}{ Sweetness } & \multicolumn{3}{|c|}{ Sourness } & \multicolumn{3}{|c|}{ Firmness } \\
\hline & $\begin{array}{c}\text { Not } \\
\text { enough }\end{array}$ & JAR & $\begin{array}{l}\text { Too } \\
\text { much }\end{array}$ & $\begin{array}{c}\text { Not } \\
\text { enough }\end{array}$ & JAR & $\begin{array}{r}\text { Too } \\
\text { much }\end{array}$ & $\begin{array}{c}\text { Not } \\
\text { enough }\end{array}$ & JAR & $\begin{array}{c}\text { Too } \\
\text { much }\end{array}$ & $\begin{array}{c}\text { Not } \\
\text { enough }\end{array}$ & JAR & $\begin{array}{c}\text { Too } \\
\text { much }\end{array}$ & $\begin{array}{c}\text { Not } \\
\text { enough }\end{array}$ & JAR & $\begin{array}{l}\text { Too } \\
\text { much }\end{array}$ \\
\hline Caddo & 4 & 79 & 17 & 27 & 68 & 5 & 46 & 48 & 6 & 12 & 49 & 38 & 12 & 80 & 7 \\
\hline Osage & 54 & 44 & 1 & 27 & 72 & 1 & 47 & 47 & 6 & 12 & 60 & 27 & 25 & 74 & 1 \\
\hline Ouachita & 36 & 60 & 4 & 41 & 47 & 12 & 77 & 23 & 0 & 4 & 32 & 64 & 15 & 73 & 12 \\
\hline Ponca & 42 & 56 & 2 & 26 & 69 & 5 & 27 & 63 & 10 & 21 & 58 & 21 & 22 & 74 & 4 \\
\hline Prime-Ark ${ }^{\circledR}$ Traveler & 25 & 62 & 10 & 47 & 49 & 4 & 59 & 36 & 5 & 21 & 43 & 36 & 17 & 70 & 12 \\
\hline
\end{tabular}

${ }^{\mathrm{z}}$ The 5-point just about right (JAR) scale ( 1 = not nearly enough; 2 = not enough; $3=\mathrm{JAR} ; 4$ = too much; $5=$ much too much) was collapsed to not enough, JAR, and too much 
acidity, and 12.8 soluble solids to titratable acidity ratio. In a consumer sensory evaluation (74 panelists) of 11 UA System genotypes, Threlfall et al. (2016b) found that 'Prime-Ark ${ }^{\circledR}$ Traveler' had the highest liking for appearance, berry size, overall impression, and overall flavor with an $8.5 \mathrm{~g}$ berry weight, $9.0 \%$ soluble solids $0.9 \%$ titratable acidity, and 10.2 soluble solids/titratable acid ratio. In terms of the liking and overall impression, both our study and the previous study showed that 'Ponca' and 'Prime-Ark ${ }^{\circledR}$ Traveler' had soluble solids/titratable acid ratio of $\approx 10 \%$ to $12 \%$.

For data analysis, the JAR data were collapsed to "Too Low," JAR, and "Too Much" (Table 3). Ideally in JAR evaluations, it is desired that at least $75 \%$ of participants consider an attribute JAR. The consumers found 'Caddo' 79\% JAR for size, whereas 'Natchez' was considered too large by 33\% of consumers, and the other cultivars were considered too small by $25 \%$ to $54 \%$ of consumers. 'Osage', 'Ponca', and 'Caddo', were $72 \%, 69 \%$, and $68 \%$ JAR for blackberry flavor, respectively. These three cultivars are the most recent floricane-fruiting releases from the UA System blackberry breeding program, and they are all considered to have excellent flavor and aromatic impact. It is also worth noting that 'Caddo' and 'Osage' are half-siblings, and they were both selected for their excellent flavor and aromatic properties (Clark et al., 2019). The consumers found that all the cultivars were $70 \%$ to $80 \%$ JAR for firmness. Threlfall et al. (2016b) also found that the 11 genotypes previously evaluated were $62 \%$ to $89 \%$ JAR for firmness.

\section{Conclusions}

The goal of this research was to identify consumer-driven attributes of fresh-market blackberries through consumer sensory evaluations, while also evaluating the physical and composition attributes of six UA System blackberry cultivars (Caddo, Natchez, Osage, Ouachita, Ponca, and Prime-Ark ${ }^{\circledR}$ Traveler). The results from the visual evaluation of individual blackberries and groups of blackberries in the clamshells were similar to the online survey of the consumer perception of fresh blackberries with 879 participants by Threlfall et al. (2020). In general, consumers preferred oblong, large blackberries as opposed to round or small. Consumers preferred to purchase clamshells containing larger blackberries and preferred blackberries without red drupelet reversion. Consumer evaluation of the appearance of the six UA system cultivars also indicated that large blackberries were preferred. The cultivars varied significantly in size: 'Natchez' had the highest berry weight (9.98 g), and 'Osage' had the lowest berry weight (4.83 g). 'Caddo', the second largest cultivar in the study, received the highest JAR rating for size (79\%), and 'Caddo' and 'Natchez' received the highest consumer ratings for fruit size on the hedonic scale.

The UA System cultivars also had composition attributes within a commercially acceptable range. 'Ponca', 'Osage', 'Caddo', and 'Natchez' were all rated highly for sweetness, sourness, overall flavor, and overall impression. 'Ponca' was particularly highly rated for sweetness, overall flavor, and overall impression and had the most ideal composition of the cultivars evaluated according to the criteria established by Threlfall et al. (2016b). 'Osage' received a JAR rating of $72 \%$ for blackberry flavor. All cultivars received high JAR scores between $70 \%$ to $80 \%$ for firmness, indicating that UA System efforts to breed blackberries for improved firmness and postharvest handling have not resulted in cultivars that consumers perceive as too firm. Identifying marketability attributes of fresh-market blackberries helps provide information to advance breeding efforts for fruit with commercial potential. As with all crops, breeding and release of new cultivars to address evolving changes and production challenges is vital to keep healthy markets.

\section{Literature Cited}

Cavender, G., M. Liu, D. Hobbs, B. Frei, B. Strik, and Y. Zhao. 2014. Effects of different organic weed management strategies on the physiochemical, sensory, and antioxidant properties of machineharvested blackberry fruits. J. Food Sci. 79:S2107S2115, doi: 10.1111/1750-3841.12639.

Clark, J.R. 2005. Intractable traits in Eastern U.S. blackberries. HortScience 40:1954-1955, doi: 10.21273/HORTSCI.40.7.1954.

Clark, J.R., M. Worthington, and T. Ernst. 2019. 'Caddo' thornless blackberry. HortScience 54:1632-1636, doi: 10.21273/HORTSCI14119-19.

de Souza, V.R., P.A.P. Pereira, T.L.T. de Silva, L.C. de Oliveira Lima, R. Pio, and F. Queiroz. 2014. Determination of the bioactive compounds, antioxidant activity and chemical composition of Brazilian blackberry, red raspberry, strawberry, blueberry and sweet cherry fruits. Food Chem. 156:362-368, doi: 10.1016/j.foodchem.2014.01.125.

Du, X.F., C.E. Finn, and M.C. Qian. 2010a. Volatile composition and odour-activity value of thornless 'Black Diamond' and 'Marion' blackberries. Food Chem. 119:1127-1134, doi: 10.1016/j.foodchem.2009.08.024.

Du, X.F., C.E. Finn, M.C. Qian, A. Kurnianta, and M. McDaniel. 2010b. Flavour profiling of 'Marion' and thornless blackberries by instrumental and sensory analysis. Food Chem. 121:1080 1088, doi: 10.1016/j.foodchem.2010.01.053.

Edgley, M., D.C. Close, and P.F. Measham. 2019a. Effects of climatic conditions during harvest and handling on the postharvest expression of red drupelet reversion in blackberries. Scientia Hort. 253:399-404, doi: 10.1016/j.scienta.2019.04.052.

Edgley, M., D.C. Close, and P.F. Measham. 2019b. Nitrogen application rate and harvest date affect red drupelet reversion and postharvest quality in 'Ouachita' blackberries. Scientia Hort. 256:1-8, doi: 10.1016/j.scienta.2019.108543.

Edgley, M., D.C. Close, P.F. Measham, and D.S. Nichols. 2019. Physiochemistry of blackberries (Rubus L. subgenus Rubus Watson) affected by red drupelet reversion. Postharvest Biol. Technol. 153:183-190, doi: 10.1016/j.postharvbio.2019.04.012.

Felts, M., R.T. Threlfall, J.R. Clark, and M.L. Worthington. 2020. Effects of harvest time (7:00 AM and 12:00 PM) on postharvest quality of Arkansas fresh-market blackberries. Acta Hort. 1277:477-486, doi: 10.17660/ActaHortic.2020.1277.68.
Finn, C.E. and J.R. Clark. 2012. Blackberry, p. 151-190. In: M.L. Badenes and D.H. Byrne (eds.). Fruit Breeding. Springer Science + Business Media, New York, NY.

Finn, C.E. and J.R. Clark. 2017. Cultivar development and selection. In: H.K. Hall and R.C. Funt (eds.). Blackberries and their hybrids. CABI, Boston, MA.

Joo, M., N. Lewandowski, R. Auras, J. Harte, and E. Almenar. 2011. Comparative shelf life study of blackberry fruit in bio-based and petroleumbased containers under retail storage conditions. Food Chem. 126:1734-1740, doi: 10.1016 j.foodchem.2010.12.071.

Kurnianta, A.J. 2005. Descriptive sensory analysis of thornless blackberry selections to determine sensory similarity to 'Marion' blackberry flavor. Ore. State Univ., Corvallis, Master's Thesis.

Mikulic-Petkovsek, M., V. Schmitzer, A. Slatnar, F. Stampar, and R. Veberic. 2012. Composition of sugars, organic acids, and total phenolics in 25 wild or cultivated berry species. J. Food Sci. 77:1064 1070, doi: 10.1111/j.1750-3841.2012.02896.x.

McCoy, J.E., J.R. Clark, A.A. Salgado, and A. Jecmen. 2016. Evaluation of harvest time/temperature and storage temperature on postharvest incidence of red drupelet reversion development and firmness of blackberry (Rubus L. subgenus Rubus Watson). Discov. Student J. Dale Bump. Coll. Agr. Food Life Sci. 17:59-65.

Perkins-Veazie, P. 2017. Postharvest storage and transport of blackberries, p. 266-282. In: H. Hall and R. Funt (eds.). Blackberries and their hybrids. CABI, Boston, MA.

Perkins-Veazie, P., J.K. Collins, and J.R. Clark. 1996. Cultivar and maturity affect postharvest quality of fruit from erect blackberries. HortScience 31:258261, doi: 10.21273/HORTSCI.31.2.258.

Salgado, A.A. and J.R. Clark. 2016. "Crispy" blackberry genotypes: A breeding innovation of the University of Arkansas blackberry breeding program. HortScience 51:468-471, doi: 10.21273/HORTSCI.51.5.468.

Segantini, D.M., R. Threlfall, J.R. Clark, C.R. Brownmiller, L.R. Howard, and L.J.R. Lawless. 2017. Changes in fresh-market and sensory attributes of blackberry genotypes after postharvest storage. J. Berry Res. 7:129-145, doi: $10.3233 / J B R-170153$.

Segantini, D.M., R.T. Threlfall, J.R. Clark, L.R. Howard, and C.R. Brownmiller. 2018. Physiochemical changes in floricane and primocane blackberries harvested from primocane genotypes. HortScience 53:9-15, doi: 10.21273/ HORTSCI12554-17.

Stafne, E.T., A. Rezazadeh, M. Miller-Butler, and B.J. Smith. 2017. Environment affects white drupelet disorder expression on three blackberry cultivars in South Mississippi. HortTechnology 27:840845, doi: 10.21273/HORTTECH03880-17.

Southern Region Small Fruits Consortium. 2020. IPM/Production Guides. 1 Sept. 2020. <https:// smallfruits.org/ipm-production-guides/>.

Threlfall, R., O. Hines, and J. Clark. 2016a. Commercial attributes of fresh blackberries identified by sensory panels. Acta Hort. 1133:391396, doi: 10.17660/ActaHortic.2016.1133.61.

Threlfall, R.T., O.S. Hines, J.R. Clark, L.R. Howard, C.R. Brownmiller, D.M. Segantini, and L.J. Lawless. 2016b. Physiochemical and sensory attributes of fresh blackberries grown in the southeastern United States. HortScience 51:1351-1362, doi: 10.21273/HORTSCI10678-16.

Threlfall, R.T., A. Dunteman, J.R. Clark, and M.L. Worthington. 2020. Using an online survey to determine consumer perceptions of freshmarket blackberries. Acta Hort. 1277:469476, doi: 10.17660/ActaHortic.2020.1277.67. 